\title{
An investigation of three patients with Christmas disease due to an abnormal type of factor ix
}

\author{
K. W. E. DENSON, ROSEMARY BIGGS, AND P. M. MANNUCCI1 \\ From the Medical Research Council, Blood Coagulation Research Unit, Churchill Hospital, Oxford
}

SYNOPSIS Three patients with Christmas disease whose plasma was shown to have a prolonged one-stage prothrombin time with ox brain thromboplastin have been investigated. These patients have an inhibitor for the reaction between factor X, factor VII, and ox brain extract. The abnormal constituent responsible for this inhibitor appears to be factor IX whuch is functionally inactive but antigenically indistinguishable from normal factor IX. It is proposed that patients might be classified into haemophilia $\mathrm{B}^{+}$for patients with this defect $\left(\right.$Christmas disease $\left.{ }^{+}\right)$and haemophilia $\mathrm{B}^{-}\left(\mathrm{Ch}^{-}\right.$ristmas disease $\left.{ }^{-}\right)$for patients who have classical Christmas disease.

In a previous communication, the plasma of an 18-month-old child with factor IX deficiency was shown to have a slightly prolonged one-stage prothrombin time with human or rabbit brain thromboplastin, and a grossly abnormal prothrombin time using ox or horse brain as thromboplastin (Kidd, Denson, and Biggs, 1963). Since this time, plasma samples from two further patients with factor IX deficiency have also been shown to have grossly prolonged clotting times in the presence of ox brain. Though the phenomenon seems to have no physiological significance the abnormality is inheritted (Hougie, and Twomey, 1967) and it was thought that it might be associated with an abnormal factor IX molecule.

\section{METHODS}

PLASMA SAMPLES Blood was collected into one tenth volume of $3.8 \%$ sodium citrate and the plasma separated by centrifuging at 3,000 rpm for 15 minutes.

OX BRAIN THROMBOPLASTIN Ox brain was collected freshly from the slaughter house and the superficial membranes were removed. It was then extracted with six to seven changes of acetone and the dried powder stored in a vacuum dessicator. For use, $0.5 \mathrm{~g}$ was suspended in $10 \mathrm{ml}$ of saline and heated at $50^{\circ} \mathrm{C}$ for 20 minutes.

HUMAN BRAIN THROMBOPLASTIN (SALINE EXTRACT) This was prepared as described by Biggs and Macfarlane (1962).

Present address: Instituto Patologia Medica, Ospedale Civelie,
Cagliari, Italy. Cagliari, Italy.

Received for publication 20 July 1967.
BOVINE FACTOR VII, FACTOR $X$, AND FACTOR IX These were prepared by column chromatography on DEAE cellulose as described by Denson (1967).

ASSAYS FOR PROTHROMBIN, FACTOR VII, AND FACTOR $\mathrm{x}$ These were performed as described by Biggs and Macfarlane (1966).

ANTIBODIES TO FACTOR VII AND FACTOR IX These were prepared as described by Denson (1967) by immunizing rabbits with the purified bovine clotting factors.

FACTOR IX INHIBITOR ASSAYS Different dilutions of plasma containing an inhibitor to factor IX were prepared in ordinary Christmas disease plasma. The dilutions were mixed with one-tenth volume of a concentrate containing factors II, VII, IX, and X, in which the factor IX concentration was 10 times that of normal plasma. The samples were then clotted in the presence of dilute brain extract and the residual factor IX was determined by the two-stage method (Biggs and Macfarlane, 1966). A graph 윽 relating inhibitor concentration and residual factor IX is shown in Fig. 1, and it can be seen that there is a linear relationship between approximately $30 \%$ and $100 \%$ of residual factor IX. The mixtures used to obtain the $\mathbb{\Omega}$ results in Table VI were similarly treated by mixing with $\mathrm{N}$ one-tenth volume of the factor IX concentrate, clotting $\mathrm{N}$ in the presence of brain extract and measuring the $\omega$ residual factor IX.

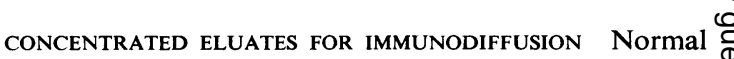
plasma, the plasma from patient 3, and Christmas disease plasma were absorbed with one-tenth volume of alumina for three minutes at $37^{\circ} \mathrm{C}$, and the factors absorbed to the alumina were eluted with one-fifth plasma volume of $0 \cdot 2 \mathrm{M}$ phosphate buffer and the eluates dia- $\frac{\varrho}{\square}$ lysed against saline and ultrafiltered to $1 / 20$ th of the $\Omega$ original plasma volume. 


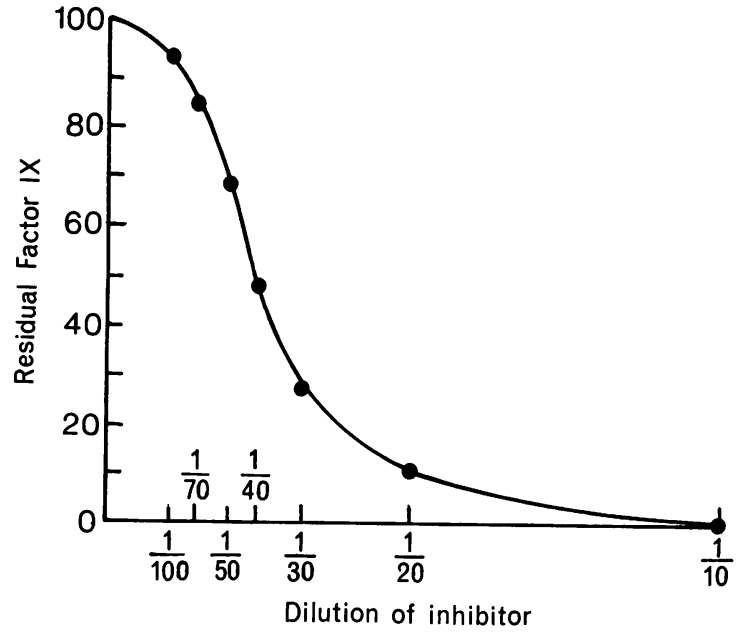

FIG. 1. Graph showing the relationship between the dilution of a factor IX inhibitor and destruction of factor IX (see Methods).

\section{RESULTS}

Table I shows that of 27 patients with Christmas disease whose plasma samples were tested using the one-stage prothrombin time and ox brain as thromboplastin only three gave a clearly prolonged clotting time. The defect would thus appear to be relatively uncommon. The three samples with markedly prolonged clotting times were tested freshly but the remaining samples were stored deep frozen and as a result might be expected to give the slightly prolonged prothrombin times which were obtained in some cases. The clotting times of all three abnormal plasma samples were shortened by the addition of normal plasma, but in mixtures of the abnormal samples one with another the clotting times remained prolonged. Although the addition of normal plasma shortened the clotting times of the abnormal samples, the clotting times were still longer than those of mixtures of normal plasma with absorbed normal plasma or factor VII-deficient plasma; this suggested the presence of some type of inhibitor rather than simple deficiency of a clotting factor. It can be seen from Table II that the clotting time is shortened to almost the same extent by factor VII-deficient, factor V-deficient, or factor-IX deficient samples as by normal plasma. Factor V concentrate, contact product or human platelet substitute, when added together with ox brain thromboplastin, were unable to shorten the clotting time. When the patient's samples were absorbed with $\mathrm{Al}(\mathrm{OH})_{3}$ and mixed with normal plasma, the clotting times were similar to the mixture of adsorbed
TABLE I

ONE-STAGE PROTHROMBIN TIMES OF SAMPLES OF FACTOR IXDEFICIENT PLASMA USING HUMAN AND OX BRAIN THROMBOPLASTIN

\begin{tabular}{llll} 
& & \multicolumn{2}{c}{ Clotting Times in Seconds } \\
\cline { 3 - 4 } & & Ox Brain & Human Brain \\
\hline Normal control samples & & 34 & $16 \cdot 5$ \\
Christmas disease plasma & $1^{1}$ & $96 \cdot 5$ & 24 \\
& $2^{2}$ & 88 & 23 \\
& 3 & 180 & $23 \cdot 5$ \\
& 4 & 39 & 19 \\
5 & 35 & 17 \\
& 6 & 29 & $15 \cdot 5$ \\
& 7 & 30 & 16 \\
8 & 33 & 15 \\
9 & 33 & 19 \\
& 10 & 35 & 19 \\
11 & 43 & 22 \\
12 & 37 & 20 \\
13 & $37 \cdot 5$ & 20 \\
14 & 37 & $19 \cdot 5$ \\
15 & $39 \cdot 5$ & $22 \cdot 5$ \\
16 & $45 \cdot 5$ & $23 \cdot 5$ \\
17 & $46 \cdot 5$ & 28 \\
18 & 29 & $16 \cdot 5$ \\
19 & 36 & $18 \cdot 5$ \\
20 & 35 & 19 \\
21 & 45 & 19 \\
22 & 43 & 18 \\
23 & 28 & $16 \cdot 5$ \\
24 & 35 & $17 \cdot 5$ \\
25 & 38 & 17 \\
$26^{3}$ & 49 & 23 \\
$27^{3}$ & 32 & 17
\end{tabular}

${ }^{1}$ Original patient referred by Dr. P. Kidd

'Patient from Italy referred by Dr. G. I. C. Ingram

${ }^{3}$ Factor IX inhibitor samples.

\section{TABLE II}

RESULTS OF ONE-STAGE PROTHROMBIN TIMES USING OX BRAIN THROMBOPLASTIN ON PLASMA FROM PATIENT 3 WITH DIFFERENT ADDITIONS

\begin{tabular}{lr} 
Sample & $\begin{array}{c}\text { Clotting } \\
\text { Time in Seco }\end{array}$ \\
\hline Normal plasma & $36 \cdot 5$ \\
Patient 3 & 246 \\
Mixtures in equal parts of:- & 80 \\
Patient 3 + normal plasma & 165 \\
Patient 3 + absorbed normal plasma & 90 \\
Patient 3 + factor VII-deficient plasma & 93 \\
Patient 3 + factor V-deficient plasma & 94 \\
Patient 3 + factor X-deficient plasma & 105 \\
Patient 3 + factor IX-deficient plasma & 280 \\
Patient 3 + factor V concentrate & 203 \\
Patient 3 + contact product & 270 \\
Patient 3 + human platelet substitute & 43 \\
Patient 3 absorbed + normal plasma & 40 \\
Normal absorbed + normal plasma & 37 \\
Normal + factor VII-deficient plasma &
\end{tabular}

normal plasma and normal plasma indicating that if an inhibitor was present this was removed by adsorption.

EFFECT OF ABNORMAL PLASMA SUPPLIES ON INTRINSIC AND EXTRINSIC FACTOR $X$ ACTIVATORS It has been shown that factor $X$ can be activated in three differ- 
ent ways: by Russell's viper venom and calcium chloride (Macfarlane, 1961); by a mixture of factor VIII, factor IXa, thrombin, and calcium chloride (Biggs, Macfarlane, Denson, and Ash, 1965) and by brain extract and calcium in the presence or absence of factor VII (Denson, 1967). The three patients' samples gave normal clotting times in the presence of Russell's viper venom and thus it was concluded that they contained nothing which inhibited or retarded the activation of factor X by Russell's viper venom. The effect of preformed intrinsic factor $\mathrm{X}$ activator on the samples was studied by incubating a mixture of factor IX, contact product, factor VIII, thrombin, and calcium chloride (Biggs et al., 1965). This mixture gave the same clotting time when added with platelet substitute to either ordinary Christmas disease plasma or the patient's samples. Similarly preformed extrinsic factor $\mathrm{X}$ activator prepared by incubating factor $X$, factor VII, ox brain, and calcium chloride gave the same clotting times when subsampled into ordinary Christmas disease plasma or the abnormal samples. When factor VII was omitted and incubation mixtures consisted of factor $\mathrm{X}$, ox brain, calcium chloride, and either normal or abnormal plasma added as a source of factor VII, the generation of factor $\mathrm{Xa}$ activity was slower in the presence of the abnormal plasma sample(Table III). The results of these experiments and previous ones indicated that the defect in the patients involved the activation of factor $\mathrm{X}$ by ox brain extract, but that the activation of prothrombin by preformed factor Xa occurred normally regardless of the method used for factor X activation. It thus seemed likely that the abnormal plasma contained an inhibitor for the reaction between ox brain thromboplastin, factor $\mathrm{X}$, and factor VII.

TABLE III

FORMATION OF ACTIVATED FACTOR X IN NORMAL AND ABNORMAL PLASMA SAMPLES

Incubation Time in Minutes

\begin{tabular}{|c|c|c|c|c|c|c|}
\hline \multirow[t]{2}{*}{$\begin{array}{l}\text { Plasma added to incubation } \\
\text { mixture }\end{array}$} & $\mathbf{0}$ & 1 & 2 & 3 & 4 & \multirow[t]{2}{*}{5} \\
\hline & \multicolumn{5}{|c|}{ Clotting Time in Seconds } & \\
\hline $\begin{array}{l}\text { Normal } \\
\text { Patient } 3 \\
\text { Normal absorbed } \\
\text { Patient } 3 \text { absorbed }\end{array}$ & $\begin{array}{r}63 \\
131 \\
174 \\
181\end{array}$ & $\begin{array}{r}10 \\
91 \\
132 \\
110\end{array}$ & $\begin{array}{l}10 \\
21 \\
78 \\
55\end{array}$ & $\begin{array}{l}12 \\
10 \\
- \\
-\end{array}$ & $\begin{array}{l}15 \cdot 6 \\
11 \\
24 \\
22\end{array}$ & $\begin{array}{l}25 \\
25\end{array}$ \\
\hline
\end{tabular}

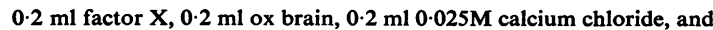
$0.2 \mathrm{ml}$ patient or normal plasma were incubated for timed intervals and $0.1 \mathrm{ml}$ subsampled into $0.1 \mathrm{ml}$ platelet substitute $+0.1 \mathrm{ml} \mathrm{0.025 \textrm {M }}$ calcium chloride. $0.1 \mathrm{ml}$ of factor $X$-deficient substrate plasma was added and the clotting times recorded.

ASSAYS FOR FACTORS VII AND $x$ Table IV shows that assays for both factor VII and factor X using human brain extract were within normal limits for all three

\section{TABLE IV}

RESUlTS OF FACTORS VII, II, AND X ASSAYS ON PLASMA SAMPLES FROM THE THREE PATIENTS

Percentage Percentage Percentage Factor VII Factor $X \quad$ Factor II

\begin{tabular}{lrrrl} 
Patient & $\begin{array}{l}\text { Ox Brain } \\
\text { Thromboplastin }\end{array}$ & $\begin{array}{l}\text { Human Brain } \\
\text { Thromboplastin }\end{array}$ \\
\hline 1 & 88 & 74 & 96 & 112 \\
2 & 75 & 60 & 90 & -136 \\
3 & 107 & 117 & 104 & 136
\end{tabular}

patients. The curves in Fig. 2A show the effect on the clotting time of adding (a) different dilutions of normal plasma and (b) dilutions of one of the abnormal samples to factor VII-deficient plasma i and testing the clotting times in the presence of ox $\vec{\sigma}$ brain. In the range of dilutions normally tested in assay procedures, between 1 in 10 and 1 in 100, the 9 clotting times for the dilutions of the abnormal $\vec{z}$ sample approximated the clotting times of the normal plasma dilutions. When dilutions between $\widehat{\widehat{A}}$ 1 in 1 and 1 in 10 were added, the clotting times of the abnormal sample dilutions were all much longer $\vec{\bullet}$ than the clotting times of the normal plasma dilu- 9 tions. These curves again suggested the presence of an inhibitor in the normal sample to reactions between factor VII, factor X, and ox brain. Figure 2B shows the results of similar experiments performed using factor X-deficient plasma and it can $\stackrel{\odot}{\triangle}$ be seen that the same general pattern of inhibition $\vec{F}$ is obtained with the higher concentrations of the abnormal sample.

A

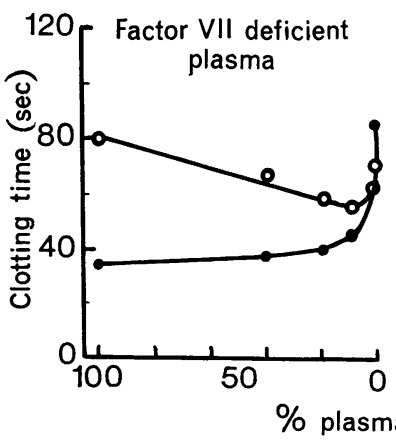

FIG. 2. Factor-VII-deficient or factor-X-deficient sub-疋 strate plasma $0.1 \mathrm{ml}$ was mixed with 0.1 of a dilution of: normal or abnormal sample in citrate saline; $0.1 \mathrm{ml}$ of ox $\square$ brain thromboplastin was added and the mixture incubated $\overline{0}$ at $37^{\circ} \mathrm{C} ; 0.1 \mathrm{ml}$. of $0.05 \mathrm{MCaCl}$ was added and the clotting time recorded.

$\%$ dilution normal plasma, $\times-\times-\times$

$\%$ dilution abnormal plasma, $\mathrm{O}-\mathrm{O}-\mathrm{O}$. 
EFFECT OF ADDING PURIFIED PREPARATIONS OF FACTOR VII AND FACTOR X ON ONE-STAGE PROTHROMBIN TIMES OF THE ABNORMAL SAMPLE The mechanism of the reaction involving ox brain extract, factor VII, and factor $\mathrm{X}$ has not been defined and it is thus difficult to study the kinetics of its inhibition; nevertheless it is worthwhile recording the results of experiments involving the use of purified concentrates of factors VII and X.

One-stage prothrombin times were carried out on normal plasma and plasma from patient 3 using ox brain extract with the addition of different concentrations of ox factor VII or ox factor $X$ and with varying concentrations of both factors. The results are shown in Fig. 3 and have been plotted by the Lineweaver-Burke method on the assumption that the clotting times are directly related to the reciprocal of the velocity of the reaction. The inhibitor appears to act competitively in a reaction involving both factors VII and X since at infinite concentration of both factors the inhibitory activity is eliminated.

NATURE AND ORIGIN OF THE INHIBITOR One characteristic feature of the ox brain thromboplastin inhibitor was that it was removed by adsorption of the plasma with aluminium hydroxide (see Tables II and III), and thus was associated with the fraction containing prothrombin, factor VII, factor IX, and factor X. A similar abnormal reaction to ox brain has not been described in otherwise normal persons but only in association with Christmas disease, although preparations containing ox brain are widely used in modifications of the one-stage prothrombin time test. This observation, together with
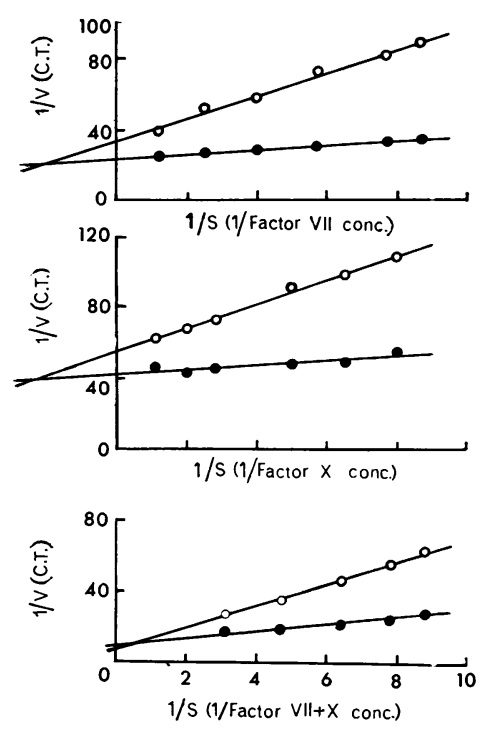

FIG. 3. One-stage prothrombin times were performed, using ox brain extract, on the following mixtures: $0.1 \mathrm{ml}$ of normal plasma or abnormal plasma; $0.1 \mathrm{ml}$ of different concentrations of factor VII, factor $X$, or a mixture of factors $V I I+X ; 0.1 \mathrm{ml}$ of ox brain extract; $0.1 \mathrm{ml}$ of $0.025 \mathrm{M} \mathrm{CaCl}_{2}$.

The highest concentration of factor VII or factor $X$ added was equivalent to nine times the concentration in normal human plasma. The reciprocals of the concentrations have been calculated to include the constant amount present in the plasma samples.

$\bigcirc-\bigcirc-\bigcirc$ Abnormal plasma (patient 3).

-O Normal plasma

\begin{tabular}{|c|c|c|c|c|c|}
\hline $\begin{array}{l}\text { Plasma } \\
\text { Sample }\end{array}$ & $\begin{array}{l}\text { Dilution of } \\
\text { Factor IX } \\
\text { Inhibitor }\end{array}$ & $\begin{array}{l}\text { Factor IX } \\
\text { Inhibitor }(1)\end{array}$ & $\begin{array}{l}\text { Factor IX } \\
\text { Inhibitor (2) }\end{array}$ & $\begin{array}{l}\text { Factor IX } \\
\text { Antiserum }\end{array}$ & $\begin{array}{l}\text { Normal Absorbed } \\
\text { Plasma (Control) }\end{array}$ \\
\hline Patient 3 & 1 in 20 & 134 & 126 & 149 & 160 \\
\hline Patient 3 & 1 in 10 & 126 & 120 & 123 & 153 \\
\hline Patient 3 & 1 in 5 & 97 & 114 & 107 & 128 \\
\hline Patient 3 & 1 in 2 & 51 & 41 & 46 & 118 \\
\hline Normal & 1 in 20 & 40 & 45 & - & 41 \\
\hline Normal & 1 in 5 & 43 & — & - & 47 \\
\hline Normal & 1 in 2 & 45 & - & - & 49 \\
\hline Christmas disease plasma & 1 in 20 & 40 & 46 & - & 40 \\
\hline Christmas disease plasma & 1 in 10 & 41 & 45 & - & 41 \\
\hline Christmas disease plasma & 1 in 5 & 46 & - & - & 42 \\
\hline Christmas disease plasma & 1 in 2 & 47 & - & - & 45 \\
\hline Patient 2 & 1 in 2 & 82 & 49 & - & 126 \\
\hline Patient 1 & 1 in 2 & 67 & 48 & - & 107 \\
\hline
\end{tabular}

Absorbed factor IX inhibitor plasma was added to the patients' samples, normal plasma or Christmas disease plasma in the proportions shown, and one-stage clotting times were performed on the mixtures using ox-brain thromboplastin. The clotting times in the last column are control values in which absorbed normal plasma was substituted for the inhibitor. 
the fact that the inhibitor is absorbed by aluminium hydroxide, suggested that it might perhaps be an abnormal protein similar to factor IX which might be inactive in its reaction with factor VIII and thus appear to be absent in biological assays for factor IX. Experiments were designed in which an antibody to factor IX and two samples from Christmas disease patients who had developed inhibitors to factor IX were used to remove factor IX from the abnormal samples. Were the inhibitor an abnormal protein similar to factor IX the removal of this abnormal protein would result in a normal clotting time with ox brain. The results in Table $V$ show that the prolonged one-stage clotting times using ox thromboplastin became normal when the patients' samples were treated with antisera or inhibitors to factor IX, but that the clotting times of normal plasma and ordinary Christmas disease plasma remained unchanged. Thus the constituent responsible for the abnormal reaction to ox brain is quantitatively removed by two different inhibitors to factor IX, and also by an antiserum to factor IX in all three patients.

Since the ox thromboplastin inhibitor was removed by the factor IX inhibitor samples it was reasonable to suppose that the factor IX inhibitor would be removed by the ox thromboplastin inhibitor in the patients' samples. An experiment was designed in which different dilutions of the two factor IX inhibitor samples were made in normal plasma, Christmas disease plasma, or plasma from patient 3. A factor IX concentrate was then added to these mixtures and the residual factor IX assayed by the two-stage method. The results appear in Table VI and show that as the proportion of normal plasma or plasma from patient 3 in the mixtures increases there is more residual factor IX and hence less inhibitor present.

It would therefore appear that these three patients have in place of normal factor IX an abnormal factor IX, which is functionally inactive but antigenically indistinguishable from normal factor IX.

DEMONSTRATION OF THE ABNORMAL PROTEIN BY IMMUNODIFFUSION Concentrated eluates were pre-

\section{TABLE VI}

REMOVAL OF FACTOR IX INHIBITORS BY THE ABNORMAL FACTOR IX IN THE PATIENTS' SAMPLE

\begin{tabular}{|c|c|c|c|}
\hline \multicolumn{3}{|c|}{$\begin{array}{l}\text { Dilution of Factor } \\
I X \quad \text { Inhibitor (I) }\end{array}$} & \multirow{2}{*}{$\begin{array}{c}\begin{array}{c}\text { Dilution of Factor } \\
\text { IX Inhibitor (2) }\end{array} \\
1 / 101 / 20\end{array}$} \\
\hline $1 / 2$ & $1 / 5$ & $1 / 10$ & \\
\hline
\end{tabular}

Plasma used as diluent

Ordinary Christmas disease Normal

Patient 3

\begin{tabular}{|c|c|c|c|}
\hline & tag & esidu & tor \\
\hline 0 & 0 & 0 & $\begin{array}{l}23 \\
54\end{array}$ \\
\hline $\begin{array}{l}\mathbf{0} \\
0\end{array}$ & $\begin{array}{r}1 \\
11\end{array}$ & $\begin{array}{l}22 \\
46\end{array}$ & $\begin{array}{l}54 \\
46\end{array}$ \\
\hline
\end{tabular}

The inhibitor samples were diluted in normal plasma, Christmas disease plasma and plasma from patient 3. The dilutions were mixed with one-tenth volume of a concentrate containing factors II, VII, IX and $X$ in which the factor IX concentration was 10 times that of normal plasma. The mixtures were then clotted in the presence of dilute brain extract and the residual factor IX was determined by the two-stage method (Biggs and Macfarlane, 1966).

prepared from normal plasma, Christmas disease plasma, and the plasma from patient 3 (see Methods), and immunodiffusion plates (Ouchterloney, 1962) prepared in which different eluates were placed in the outer wells and an antiserum to factor IX in the centre wells. The results are shown in Fig. 4, and indicate quite clearly fusion of the two precipitin lines in (a) and (b) between the factor IX antiserum and the eluates of normal plasma and the plasma of patient 3 , suggesting antigenic identity of the two components. No precipitin lines were obtained with concentrates of plasma samples from 10 different patients with Christmas disease, some of which were placed in the remaining outer wells in (a) and (b). Precipitin lines were not obtained between the naturally occurring inhibitors to factor IX and eluates from normal plasma and plasma from patient 3, confirming the observations of previous workers (Hardisty, 1962, Colombani and Terrier, 1962) who were unable to demonstrate a precipitin reaction between normal plasma and inhibitors to factor IX.

MISCELLANEOUS CHARACTERISTICS OF THE INHIBITOR 은 The inhibitor was present in serum but absent from $D$ adsorbed plasma. It was heat stable at $56^{\circ} \mathrm{C}$ for 15 을 minutes and not progressive in action during incu- $N$ bation with normal plasma. It was maximally

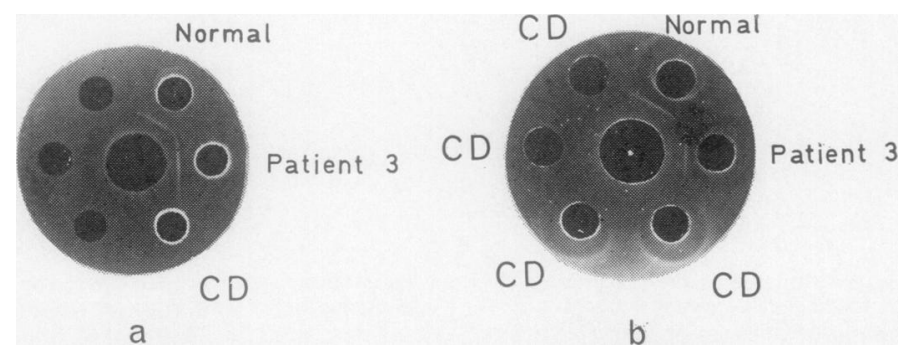

FIG. 4. Ouchterloney plates in which an antiserum to factor IX was placed in the central well and eluates from normal plasma, ordinary Christmas disease plasma $(C D)$ and plasma from patient 3 in the outer wells, as indicated. 
precipitated at 33 to $50 \%$ saturation with ammonium sulphate and was absent in the supernatant after $70 \%$ saturation with ammonium sulphate.

FAMILY STUDIES Patient 3 was unfortunately an adopted child, and the parents could not be traced. The parents of patient 1 were tested and the plasma of both gave a normal clotting time with ox brain.

Family studies are at present in progress in the case of patient 2 , who has since returned to Italy.

\section{DISCUSSION}

The exact mode of action of the inhibitor in prolonging the one-stage clotting time with ox brain is an academic curiosity which has not been elucidated. The interest of this phenomenon lies in the observation that the constituent responsible is an abnormal form of factor IX which is functionally inactive but antigenically indistinguishable from normal factor IX. The abnormal factor IX is quantitatively removed not only by an inhibitor to factor IX occurring in Christmas disease patients but also by an antibody to bovine factor IX which had previously been shown to react equally with bovine or human factor IX (Denson, 1967). Reversely the factor IX inhibitor was removed by the patients' samples but samples from patients with ordinary Christmas disease failed to neutralize the factor IX inhibitor. The abnormal factor IX protein also gave a precipitin line with a factor IX antibody which showed antigenic identity with the precipitin line of normal factor IX.

Fantl, Sawers, and Marr (1956) suggested that there might be two forms of Christmas disease since they observed that an inhibitor to factor IX in a patient with Christmas disease was neutralized by a barium sulphate absorbate from only one of three patients with Christmas disease. Hougie and Twomey (1967) have recently investigated two siblings with Christmas disease whose plasma gave an abnormal reaction to ox brain. They have suggested as a result of a family study that the patients have an abnormal type of factor IX and they proposed the term haemophilia $B_{M}$ for this type.

It is suggested on the basis of the present work in which the presence of a protein antigenically indistinguishable from factor IX has been demonstrated in the plasma of three patients with Christmas disease, that Christmas disease might be classified into two types: haemophilia $\mathbf{B}^{+}$(Christmas disease ${ }^{+}$) for the defect observed in these three patients who have an abnormal reaction to ox brain and whose blood contains a protein antigenically indistinguishable from factor IX, and haemophilia $\mathrm{B}^{-}$ (Christmas disease $^{-}$) for classical Christmas disease in which factor IX is absent. Strictly speaking 'factor IX deficiency' as a designation is applicable only to haemophilia $\mathbf{B}^{-}$. The test using ox brain thromboplastin, Two-Seven-Ten reagent, or Thrombotest is a simple means of distinguishing these two types of Christmas disease.

We wish to thank Dr. G. I. C. Ingram for his original observations on the plasma sample of patient 2 and for arranging for one of us (P.M.) to study this abnormality. We are grateful to Dr. P. Kidd for referring patient 1 and for obtaining blood from the relatives.

\section{REFERENCES}

Biggs, R., and Macfarlane, R. G. (1962). Human Blood Coagulation and its Disorders, 3rd ed. Blackwell, Oxford.

- - (1966). The Treatment of Haemophilia and other Coagulation Disorders. Blackwell, Oxford.

,$- \frac{1}{11}$, Denson, K. W. E., and Ash, B. J. (1965). Brit. J. Haemat., 11, 276.

Colombani, J., and Terrier, E. (1962). Nature (Lond.), 196, 1111.

Denson, K. W. E. (1967). The Use of Antibodies in the Study of Blood Coagulation. Blackwell, Oxford.

Fantl, P., Sawers, R. J., and Marr, A. G. (1956). Aust. Ann. Med., $5,163$.

Hardisty, R. M. (1962). Thrombos. Diathes. haemorrh. (Stuttg.) 8, 67. Hougie, C., and Twomey, J. J. (1967). Lancet, 1, 698.

Kidd, P., Denson, K. W. E., and Biggs, R. (1963). Ibid., 2, 522.

Macfarlane, R. G. (1961). Brit. J. Haemat., 7, 496.

Ouchterloney, O. (1962). Progr. Allergy', 6, 30. 